TÄ̈ CHÍ PHAÙ TRIEÅ KH\&CN, TAR̈ 16, SOÁK1- 2013

\title{
HIGH POWER CONTINUOUS-WAVE 1064 NM DPSS LASER FOR MACHINING SEMICONDUCTOR AND METAL MATERIALS
}

\author{
Phan Thanh Nhat Khoa, Dang Mau Chien \\ Laboratory for Nanotechnology, VNU-HCM \\ (Manuscript Received on April 5 ${ }^{\text {th }}$, 2012, Manuscript Revised May 15 ${ }^{\text {th }}$, 2013)
}

ABSTRACT: A diode-pumped solid-state (DPSSL) laser system with $808 \mathrm{~nm}$ laser as pump source has been developed successfully. We used the optically anisotropic crystal $\mathrm{Nd:YVO}$ as the active medium. The threshold pump power and slope efficiency were measured and discussed. With lowly doped crystal Nd: $\mathrm{YVO}_{4} 0.27 \%$ and concave-plane cavity, the laser showed good performance in the pumping range up to $11 \mathrm{~W}$. Using the $1064 \mathrm{~nm}$ beam, micromachining were successfully conducted upon some normal materials such as plastic, wood; some semiconductors such as silicon and metals such as aluminum, copper, steel.

Keywords: $\mathrm{Nd}: Y A G, \mathrm{Nd}: \mathrm{YVO}_{4}, \mathrm{DPSSL}$, threshold power, slope efficiency.

\section{INTRODUCTION}

In the late 1980s, laser diode at $808 \mathrm{~nm}$ with reasonable price made its first debut on the market and many scientists turned their attention to it in searching for an alternative pump source for Nd:YAG (yttrium aluminum garnet doped with neodymium) and other Ndhosted laser. Previously, the main pump source for $\mathrm{Nd}: \mathrm{YAG}$ laser and his relatives were flash lamp. Flash lamp spectrum is broad, while 808 $\mathrm{nm}$ laser diode spectrum is much narrower, so the Nd-hosted crystal absorbs most of the power of the laser diode. In addition to that, diode-pumped $\mathrm{Nd}$ : hosted laser has many advantages over flash lamp-pumped $\mathrm{Nd}$ :hosted laser such as lifetime and compactness. The reason to use $808 \mathrm{~nm}$ laser to create $1064 \mathrm{~nm}$ laser is the beam quality: $808 \mathrm{~nm}$ laser is very powerful, yet its beam quality (especially divergence) ranks as the worst in all laser types.

Since the appearance of this new pump source and the advancing achievements in crystal growth technology, a series of new active medium has been developed: $\mathrm{Nd}: \mathrm{YVO}_{4}$, $\mathrm{Nd}: \mathrm{GdVO}_{4}$ and Nd:glass, among which $\mathrm{Nd}: \mathrm{YVO}_{4}$ (yttrium orthovanadate doped with neodymium) is the most interesting material. This material has absorption cross section at $808 \mathrm{~nm}$ and emission cross section at $1064 \mathrm{~nm}$ much greater than that of Nd:YAG [1]. This makes the $\mathrm{Nd}: \mathrm{YVO}_{4}$ laser has a much lower lasing threshold than Nd:YAG laser. However, the thermal conductive coefficient of $\mathrm{Nd}: \mathrm{YVO}_{4}$ is smaller than that of $\mathrm{Nd}: \mathrm{YAG}$, thus heat management for $\mathrm{Nd}: \mathrm{YVO}_{4}$ is more difficult. Therefore, Nd:YAG laser has been being replaced by $\mathrm{Nd}: \mathrm{YVO}_{4}$ laser in only low and medium output power modules. 
The temperature of $808 \mathrm{~nm}$ pump laser diode is also very important. The $\mathrm{p}-\mathrm{n}$ junction, which emits $808 \mathrm{~nm}$ beam when injected with electrical current, also emits an amount of heat equal to approximately $50 \%$ of the input electrical power. High temperature at the laser diode does not only shorten the life of the laser, but in case of excessively high temperature, can even result in instant death of the laser diode.

Active medium temperate also needs decent concern. When absorbing $808 \mathrm{~nm}$ beam from the pump laser diode, $\mathrm{Nd}: \mathrm{YVO}_{4}$ use part of it to generate $1064 \mathrm{~nm}$ (and then $532 \mathrm{~nm}$ ) beam, the rest absorbed pump power wastes as heat inside the crystal. The crystal may fracture under steep temperature gradient [2], and the $532 \mathrm{~nm}$ output also decreases. Below the fracture limit, temperature gradient still causes bad effect, among which thermal lens [3] is the most annoying. Doping concentration plays very important role in $\mathrm{Nd}: \mathrm{YVO}_{4}$ laser [4] due to the low thermal conductivity of $\mathrm{Nd}: \mathrm{YVO}_{4}$.

In this work, a laser pumped by $808 \mathrm{~nm}$ laser diode was constructed. The laser operated in continuous wave $(\mathrm{CW})$ mode. The active medium investigated was $\mathrm{Nd}: \mathrm{YVO}_{4}$ crystals. Threshold power and slope efficiency were measured and compared. The output $1064 \mathrm{~nm}$ beam was tested on plastic, wood, paper; semiconductors such as amorphous silicon and crystalline silicon wafer; metals such as aluminum, copper and steel.

\section{OPERATION OF 1064 NM DPSS LASER}

\subsection{Effect of laser cavity configuration}

Laser cavity can be of plane-plane, concave-plane, concave-concave, concaveconvex... forms. Each configuration has different stability, efficiency, compactness and other characteristics. One has to base on the application requirements to choose the suitable configuration.

In this study, we use two kinds of configuration: plane-plane and concave-plane. The former cavity is very compact yet its efficiency is not as good as the latter. Further details are in the result and discussion section.

\subsection{Effects of laser cavity parameters}

Mirror's radius of curvature, cavity length, position of the $\mathrm{Nd}: \mathrm{YVO}_{4}$ crystal within the cavity all affect, more or less, the performance of the laser. The effects do not limit only to the power of the $1064 \mathrm{~nm}$ beam, but also many other features. In this paper, we study the effect of cavity length on the threshold pump power (the minimum power of $808 \mathrm{~nm}$ beam pumped required for the laser to start emit $1064 \mathrm{~nm}$ beam) and slope efficiency (the slope of the input-output line).

The cavity stability [2] is characterized by the $G$ parameter which must satisfy the inequality (2):

$$
\text { (1) } G=\left(1-\frac{L}{R_{1}}\right)\left(1-\frac{L}{R_{2}}\right)
$$

(2) $0 \leq G \leq 1$ 
Where $\mathrm{L}(\mathrm{mm})$ is the cavity length (distance between two mirrors), $\mathrm{R}_{1}$ and $\mathrm{R}_{2}$ are radii of curvature of mirror 1 and 2 , respectively. Cavity with $\mathrm{G}=0.5$ has good stability (diffraction loss in the cavity is rather small, so with a low pump power the cavity can emit great amount of laser beam); while cavity with $\mathrm{G}<0$ or $\mathrm{G}>1$ is unstable (diffraction loss becomes so severe that the cavity can not emit any laser beam at any level of pump power). Cavities with $G=0$ or 1 is on the edge of stability, they may emit laser beam, but only at high pump power, and with slight vibration or shock the cavity may cease to emit laser beam completely.

The plane-plane cavity has infinite $\mathrm{R}_{1}$ and $\mathrm{R}_{2}$, naturally it does not satisfy the inequality (2) and can not emit any $1064 \mathrm{~nm}$ beam at all. However, in our experiment, it still emits. We will discuss this anomaly in the result and discussion section. For the concave-plane cavity in our study, $R_{2}$ is infinite, so the stability condition can be expressed as:

(3) $0<L<R_{1}$

Where $R_{1}$ is the curvature of the concave mirror.

From (3) we can see that, theoretically, the laser system start can not emit any $1064 \mathrm{~nm}$ beam at all when the cavity length exceeds $R_{1}$. However, in our experiment, the cavity went unstable and ceased emitting $1064 \mathrm{~nm}$ when the cavity length is $112 \mathrm{~mm}$. This will also be presented and discussed our paper.

Inside the laser cavity, the $1064 \mathrm{~nm}$ beam forms a standing wave. Its fundamental transverse mode varies as described in Figure 1.

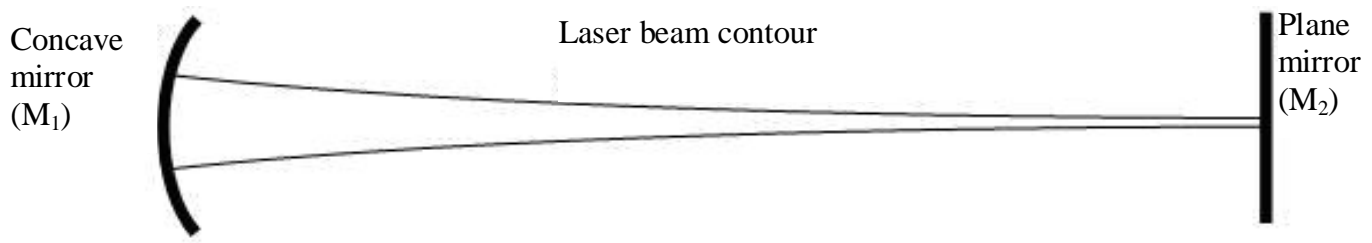

Figure 1. Fundamental transverse mode of $1064 \mathrm{~nm}$ beam inside the concave-plane cavity

The distance between the beam waist (the location where the diameter of the laser beam is smallest) to mirror 2 is given by [5]:

(4) $L_{2}=\frac{L\left(R_{1}-L\right)}{\left(R_{1}+R_{2}-2 L\right)}$

In concave-plane cavity, $\mathrm{R}_{2}=\infty$ so:

(5) $L_{2}=0$
Which mean the $1064 \mathrm{~nm}$ beam waist lies right on the plane mirror. On the other mirror (mirror 1) it has the diameter [2]:

(6)

$\omega_{1}^{4}=\left(\frac{\lambda R_{1}}{\pi}\right)^{2} \frac{\left(R_{2}-L\right)}{\left(R_{1}-L\right)} \frac{L}{\left(R_{1}+R_{2}-L\right)}$

Again, in concave-plane cavity, $\mathrm{R}_{2}=\infty$ so: 
(7) $\omega_{1}^{4}=\left(\frac{\lambda R_{1}}{\pi}\right)^{2} \frac{L}{\left(R_{1}-L\right)}$

From equations (5) and (7) and the laser beam contour in Figure 1, we can see the beam has its waist on plane mirror and then it diverges with position nearer to concave mirror.

Through (7), we can see that when the cavity length increases from 0 to $\mathrm{R}_{1}$, the beam diameter on concave mirror increases from 0 to infinitive. According to D.G. Hall [6], to achieve high efficiency, the smaller the ratio $\omega_{p} / \omega_{l}$ (where $\omega_{p}, \omega_{l}$ are the waists of

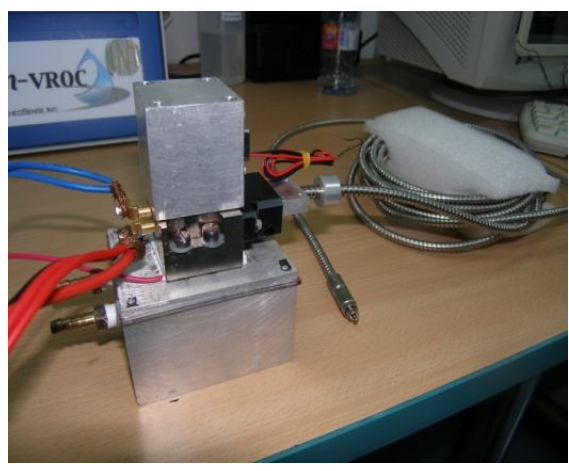

A the $808 \mathrm{~nm}$ pumping beam and $1064 \mathrm{~nm}$ lasing beam, respectively) the better. Because the waist of $808 \mathrm{~nm}$ pumping beam in this experiment is kept constant, we expected that longer cavity would have lower ratio $\omega_{p} / \omega_{l}$ and thus give higher power of $1064 \mathrm{~nm}$ beam, and when $L$ is approximately to $R_{1}$ we will achieve the highest output power. However, the fact is in the opposite.

\section{EXPERIMENT}

In our setup, we used a $808 \mathrm{~nm}$ laser diode (capable of emitting $20 \mathrm{~W}$ beam power) from Spectra Physics, USA to pump the crystal.

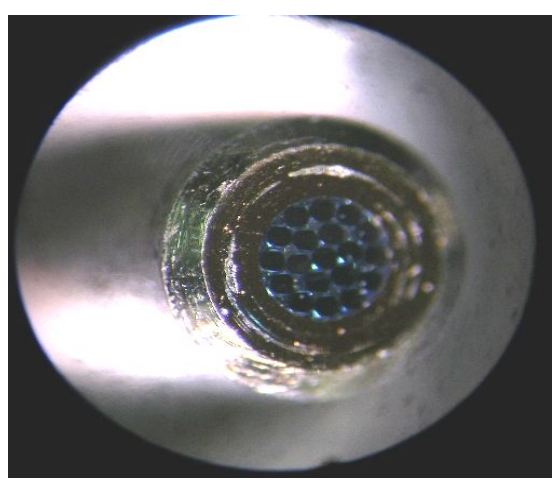

b

Figure 2. Fiber-coupled laser diode (a) and the output bundle tip under microscope (b). Note the 19 fibers arranged into a round tip in (b)

The laser diode beam was coupled in a bundle of 19 fibers, whose total core diameter is $1100 \mu \mathrm{m}$, and imaged into the crystal through a lens system which has the imaging ratio 1.6:1. The waist of $808 \mathrm{~nm}$ beam inside $\mathrm{Nd}: \mathrm{YVO}_{4}$ crystal is therefore $687.5 \mu \mathrm{m}$.

In the setup of plane-plane cavity (Figure $3)$, the active medium was $\mathrm{Nd}: \mathrm{YVO}_{4}$ doped $1 \%$ reflection (HR) thin films at $1064 \mathrm{~nm}$ on face $S_{1}$ and antireflection (AR) thin films at $1064 / 808 \mathrm{~nm}$ on face $S_{2}$. Face $S_{1}$ and the mirror 4 form a plane-plane cavity.

$(3 \times 3 \times 2 \mathrm{~mm})$. The crystal is coated high 


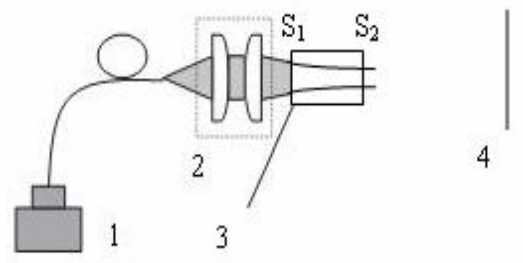

Figure 3. Setup of the laser system with plane-plane cavity. 1: Diode laser; 2: coupling lenses; 3 :

$\mathrm{Nd}: \mathrm{YVO}_{4} ; 4$ : output mirror

In the setup of concave-plane cavity (Figure 4), the active medium were $\mathrm{Nd}: \mathrm{YVO}_{4}$ doped $0.27 \%(3 \times 3 \times 12 \mathrm{~mm})$. The crystal is coated antireflection (AR) thin films 1064/808 on both sides. The concave mirror is coated HR1064 and radius of curvature $100 \mathrm{~mm}$. The plane mirror is coated with transmission $\mathrm{T}=20 \%$ at $1064 \mathrm{~nm}$ The concave face of mirror 3and the plane mirror 5 form a concave-plane cavity.

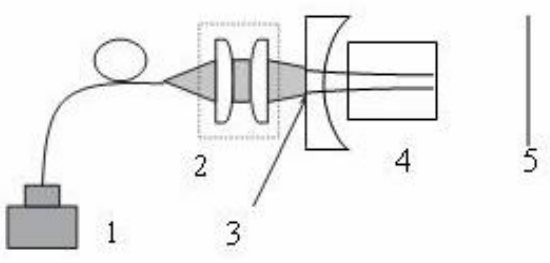

Figure 4. Setup of the laser system with concaveplane cavity. 1: Diode laser; 2: coupling lenses; 3 : Input mirror $\mathrm{M}_{1} ; 4: \mathrm{Nd}: \mathrm{YVO}_{4} ; 5$ : output mirror

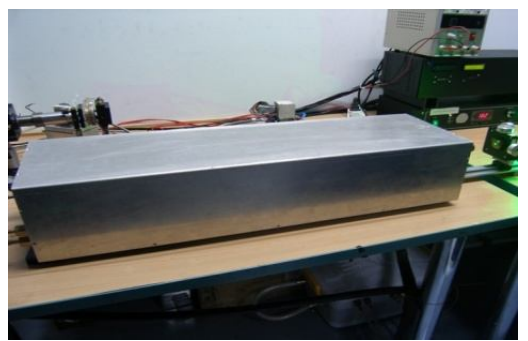

Figure 5. The laser packaged into box and is used in second harmonic generation experiment at LNT.
A $808 \mathrm{~nm}$ filter was used to cut all residual $808 \mathrm{~nm}$ beam from the $1064 \mathrm{~nm}$ output beam. The crystals, mirrors and filters are all from Casix, China.

The power of $1064 \mathrm{~nm}$ output beam was measured with the integrated sphere S142C and power meter PM100D from Thorlabs, USA

The laser beam was used to etch and cut several materials including wood, plastic; aluminum, copper, steel and silicon wafer. The etching geometries were inspected with metallurgical microscope GX51 (Olympus, Japan) and Scanning Electron Microscope JSM-6480LV (Jeol Inc, Japan) at LNT.

\section{RESULT AND DISCUSSION}

\subsection{Performance of the lasers}

The laser system with plane-plane cavity started to emit $1064 \mathrm{~nm}$ beam when the power of the pumping $808 \mathrm{~nm}$ beam exceeded 1.26 W. Figure 6 is the graph of $1064 \mathrm{~nm}$ beam versus $808 \mathrm{~nm}$ beam (cavity length $\mathrm{L}=50 \mathrm{~mm}$ ). At $11.26 \mathrm{~W}$ of $808 \mathrm{~nm}$ beam, a maximum 2.8 $\mathrm{W}$ of $1064 \mathrm{~nm}$ beam was collected.

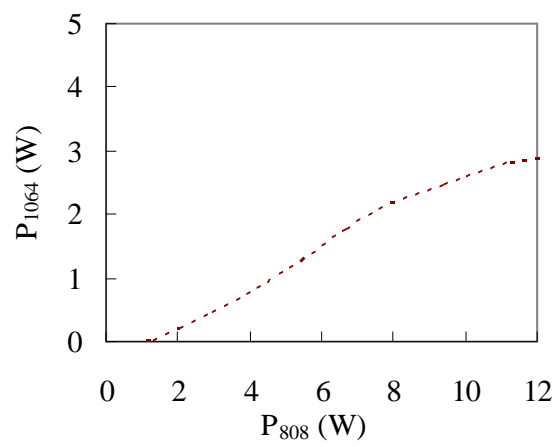

Figure 6. Output versus input of plane-plane cavity,

$$
\mathrm{L}=50
$$


Why the plane-plane cavity can be capable of emitting $1064 \mathrm{~nm}$, while conditions (1) and (2) state that is impossible? The reason may be the thermal lens in $\mathrm{Nd}: \mathrm{YVO}_{4}$ : part of $808 \mathrm{~nm}$ beam absorbed by $\mathrm{Nd}^{3+}$ ion in YAG lattice does not help generate $1064 \mathrm{~nm}$ beam, but wastes as heat. This heat creates a temperature gradient in $\mathrm{Nd}: \mathrm{YVO}_{4}$ and thus a gradient of refractive index. Medium with refractive index gradient bends light that propagates through it, thus acts as a lens. The $\mathrm{G}$ parameter of a cavity with internal lens is:

$$
\text { (8) } G=\left(1-\frac{L_{2}}{f}-\frac{L}{R_{1}}\right)\left(1-\frac{L_{1}}{f}-\frac{L}{R_{2}}\right)
$$

With $R_{1}, R_{2}$ equal to infinitive, the condition (2) now becomes:

$$
\text { (9) } 0 \leq\left(1-\frac{L_{2}}{f}\right)\left(1-\frac{L_{1}}{f}\right) \leq 1
$$

Thus the thermal lens inside $\mathrm{Nd}: \mathrm{YVO}_{4}$ somewhat stabilizes the cavity. However, this cavity was still rather vulnerable to vibration: small vibration caused the laser output drop drastically, and sometimes disappear completely.

Table 1 lists the power of $1064 \mathrm{~nm}$ beam at 6.64 and $11.26 \mathrm{~W}$ of $808 \mathrm{~nm}$ pump power, with various cavity lengths. Through the table, one can see that shorter cavity has higher efficiency.

From Figure 6, we can see the graph is linear in the pumping range from 0 to around 7 $\mathrm{W}$, this is the good working range of this laser, after that there is a drop in slope efficiency.
Pumping more $808 \mathrm{~nm}$ beam caused our crystal to crack and become permanently useless. This is due to the high doping concentration of $\mathrm{Nd}^{3+}$. In laser with $\mathrm{Nd}: \mathrm{YVO}_{4} \quad 0.27 \%$, this phenomenon did not occur.

In the good working range, the relation between input-output in this plane-plane cavity can be expressed with the equation (10):

$$
\text { (10) } P_{1064}=26 \%\left(P_{808}-1.26\right)
$$

Where $\mathrm{P}_{808}$ and $\mathrm{P}_{1064}$ are power of input and output beam, in Watt(s), $26 \%$ is the slope efficiency, and $1.26 \mathrm{~W}$ is the threshold power.

Table 1. Output at P808 $=6.64$ and $11.26 \mathrm{~W}$ from plane-plane cavity

\begin{tabular}{|c|c|c|}
\hline $\begin{array}{c}\mathrm{L} \\
(\mathrm{mm})\end{array}$ & $\begin{array}{c}\mathrm{P}_{1064} \text { at } \\
\mathrm{P}_{808}=6.64 \mathrm{~W}\end{array}$ & $\begin{array}{c}\mathrm{P}_{1064} \text { at } \\
\mathrm{P}_{808}=11.26 \mathrm{~W}\end{array}$ \\
\hline 10 & 2.02 & 3.71 \\
\hline 13 & 2.05 & 3.67 \\
\hline 20 & 1.87 & 3.68 \\
\hline 35 & 1.93 & 3.56 \\
\hline 40 & 1.93 & 3.35 \\
\hline 45 & 1.88 & 3.19 \\
\hline 50 & 1.74 & 2.8 \\
\hline 70 & 1.79 & 2.85 \\
\hline
\end{tabular}

Figure $7 \mathrm{a}$ andFigure $7 \mathrm{~b}$ shows the graph of input versus output in concave-plane cavity. The first thing to remark is the stability with respect to cavity length. As stated in (3), cavity with $\mathrm{L}$ longer than $100 \mathrm{~mm}$ (value of $\mathrm{R}_{1}$ ) can not emit laser beam. However, from the graph, we can see that at even $\mathrm{L}=100 \mathrm{~mm}$, the cavity still emitted $1064 \mathrm{~nm}$ beam, and from the data collected we see that the $112 \mathrm{~mm}$ long cavity 
still emitted $10 \mathrm{~mW}$ of $1064 \mathrm{~nm}$ when pumped at $11.26 \mathrm{~W}$. This, once again, can be the effect of thermal lens said above.
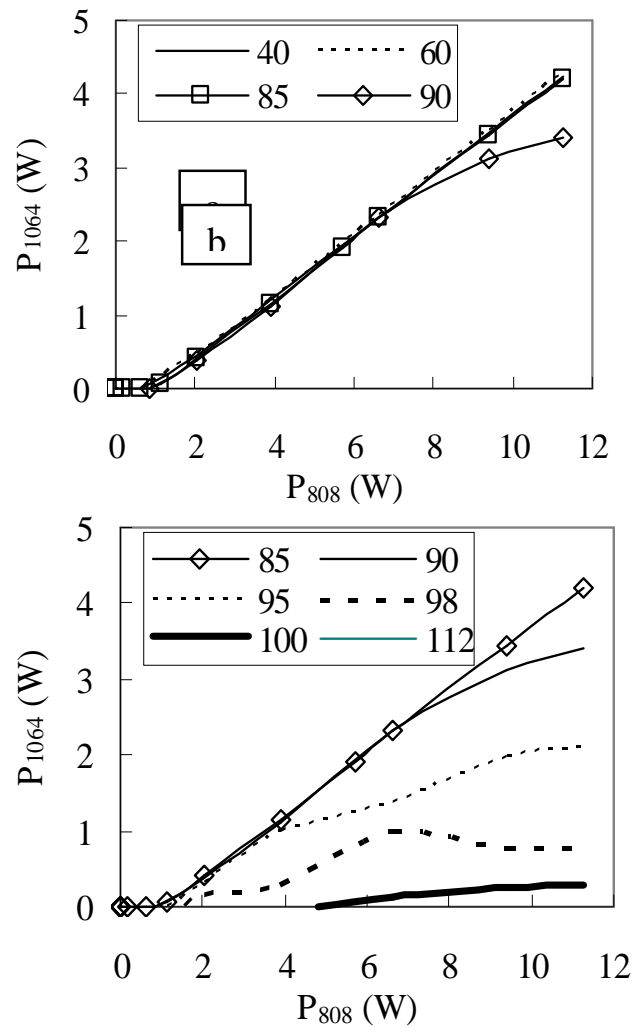

Figure 7. Output versus input of concave-plane cavity

We can also see that cavities with length from 40 to $85 \mathrm{~mm}$ are nearly identical to each other, and show complete linearity over the pumping range. Maximum output of $1064 \mathrm{~nm}$

Table 2lists the threshold powers $\mathrm{P}_{\text {th }}$ of concave-plane cavity at different cavity length. was achieved with the $60 \mathrm{~mm}$ long cavity (approximately $4.3 \mathrm{~W}$ of $1064 \mathrm{~nm}$ beam when pumped at $11.26 \mathrm{~W}$ of $808 \mathrm{~nm}$ beam). Fitting the real data with the least square method, we received the values of fitted threshold power and fitted slope efficiency. The slopes of the lines are approximately $37 \%$ and the threshold power (the minimum power of $808 \mathrm{~nm}$ beam pumped required for the laser to start emit 1064 $\mathrm{nm}$ beam) is $0.49 \mathrm{~W}$. Therefore, the inputoutput relation can be expressed with the expression (11):

$$
\text { (11) } P_{1064}=37 \%\left(P_{808}-0.49\right)
$$

With cavity length longer than $85 \mathrm{~mm}$, the laser began to show degradation, and sometimes plus chaos, in slope efficiency. The effect became more apparent with longer cavity. The $98 \mathrm{~mm}$ long cavity showed very chaotic slope. In addition, threshold became larger.

Table 2. Threshold power of concave-plane cavity

\begin{tabular}{|c|c|c|c|c|c|c|c|c|c|}
\hline $\mathrm{L}(\mathrm{mm})$ & 40 & 53 & 60 & 85 & 90 & 95 & 98 & 100 & 112 \\
\hline $\mathrm{P}_{\mathrm{th}}(\mathrm{W})$ & 0.51 & 0.48 & 0.49 & 0.50 & 0.83 & 1.11 & 2.03 & 4.8 & 11 \\
\hline
\end{tabular}


As we mentioned in the previous part, Hall D. G. stated that the smaller the ratio $\omega_{p} / \omega_{l}$ (where $\omega_{p}, \omega_{l}$ are the waists of the $808 \mathrm{~nm}$ pumping beam and $1064 \mathrm{~nm}$ lasing beam, respectively) the better for efficiency. The $\mathrm{Nd}: \mathrm{YVO}_{4}$ crystal is placed very close to the concave mirror, because the $808 \mathrm{~nm}$ beam waist right there, and we can from the equation (7) see that cavity with longer length has larger beam diameter on concave mirror, thus a lower $\omega_{p} / \omega_{l}$. On the contrary, the $\mathrm{G}$ parameter approaches unity when $\mathrm{L}$ approaches the value of $\mathrm{R}_{1}$, the cavity stability decrease with longer cavity. These two opposite trends lead to a compromise: a $\mathrm{L}$ value to balance between the $\omega_{p}, \omega_{l}$ ratio and the $\mathrm{G}$ parameter. That is why the $60 \mathrm{~mm}$ long cavity showed the best performance.

From the results, we can see that planeplane cavity with $\mathrm{Nd}: \mathrm{YVO}_{4} 1 \%$ can be used to

\subsection{Investigation in application}
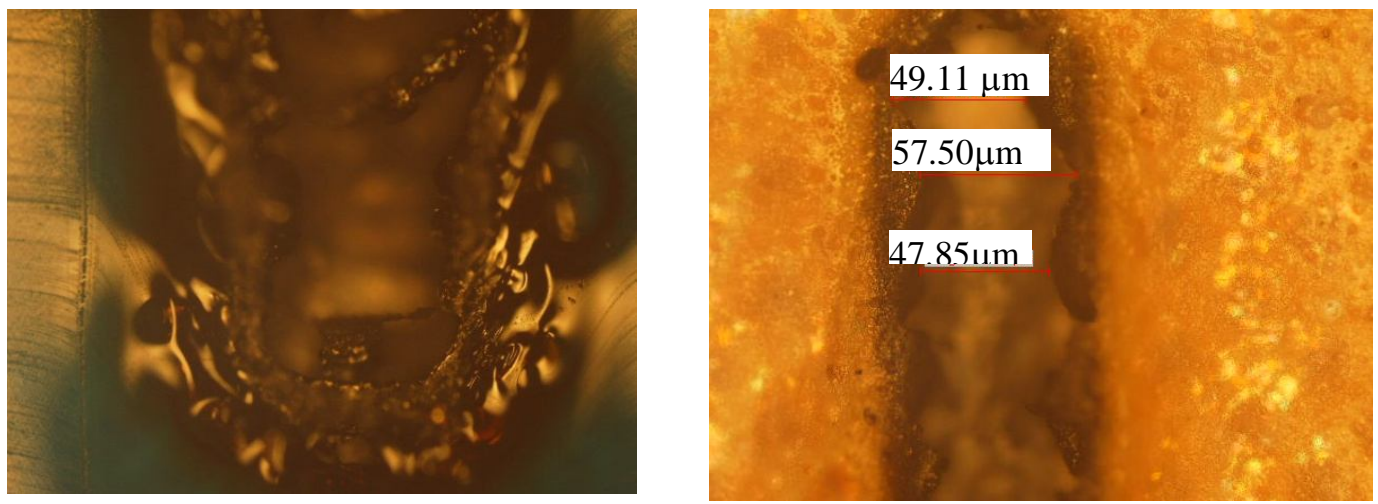

Figure 8. Etched groove on plastic sheet (a) and on wood sheet (b) under metallurgical microscope produce compact laser (the cavity length can goes down to $10 \mathrm{~mm}$ ). However, in terms of output $1064 \mathrm{~nm}$ beam power and electrical saving, concave-plane cavity with $\mathrm{Nd}: \mathrm{YVO}_{4}$ $0.27 \%$ is the better choice: with the same amount of electrical power driven into the 808 $\mathrm{nm}$ laser diode, one can acquire more powerful $1064 \mathrm{~nm}$ beam from concave-plane $\mathrm{Nd}: \mathrm{YVO}_{4}$ $0.27 \%$ laser.

In practical usage, we also notice the concave-plane cavity is much more resistant to vibration than the plane-plane cavity. Strong vibration may make the former power's output drop, but only in small amount. In no experience have we ever seen the $1064 \mathrm{~nm}$ beam disappeared completely due to strong vibration. Test on misalignment sensitivity needs to be carried out to quantitatively determine the reliability of this laser in harsh working conditions (against shock and/or vibration). This laser, however, is promising in practical usage and commercial production. 
The $1064 \mathrm{~nm}$ beam was tested on several materials and is capable of cutting through plastic and wood. Figure 8 shows etched grooves on plastic and wood. For aluminum and copper in thin layer form, the laser beam can also etch, and the etching threshold (minimum power of $1064 \mathrm{~nm}$ beam to etch) is about $0.5 \mathrm{~W}$. However, etching capability on bulk aluminum and copper is very weak.

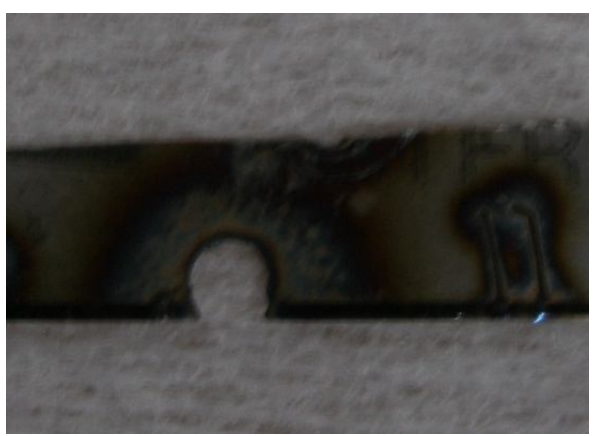

Figure 9. Photograph of cut-through hole on $100 \mu \mathrm{m}$ steel plate $(b)$

For steel, the threshold power for etching is not high: about $2 \mathrm{~W}$. The low threshold for etching steel may be due to low thermal conductivity of steel compared to silicon: 18 $\mathrm{W} / \mathrm{m}^{-1} \mathrm{~K}^{-1}$ versus $130 \mathrm{~W} / \mathrm{m}^{-1} \mathrm{~K}^{-1}$. Etching steel by $1064 \mathrm{~nm}$ beam is much easier than etching silicon, to the degree that there was spark during etching (the steel particles being burnt with atmospheric oxygen), and after 5 minutes of etching a circle groove at the same position on the steel plate, we can cut through and create a hole, as in Figure 9.

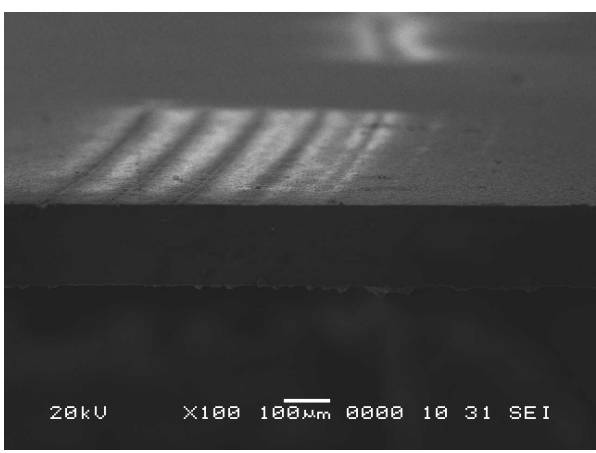

Figure 10. SEM images of etched groove on 200 $\mu \mathrm{m}$ thick silicon wafer

Figure 10is the SEM images of 11 etched grooves on $200 \mu \mathrm{m}$ thick silicon wafer under different power of $1064 \mathrm{~nm}$ beam. The lens used to concentrate the beam power has the focal length $50 \mathrm{~mm}$. From left to right, the powers of the $1064 \mathrm{~nm}$ beam are $5 \mathrm{~W}, 5 \mathrm{~W}, 5$ $\mathrm{W}, 3.86 \mathrm{~W}, 3 \mathrm{~W}, 2.3 \mathrm{~W}, 1.45 \mathrm{~W}, 0.75 \mathrm{~W}, 0.56$ $\mathrm{W}$ and $0.37 \mathrm{~W}$. We can see only the first six grooves through SEM image, thus the etching threshold for this material is $2.3 \mathrm{~W}$. The existence of this high threshold originates from the local temperature reached. The local temperature is decided by the heat per unit volume of silicon generated when silicon absorbs the $1064 \mathrm{~nm}$ and the heat dissipated to the surrounding area. Silicon has higher thermal conductivity than that of wood, plastic, thus a more powerful beam is required to make the local temperature reaching burning point.

In this study, we have not yet perform test with lens of other focal length. The etching threshold when using lens of shorter focal length is expected to be lower and vice versa. 


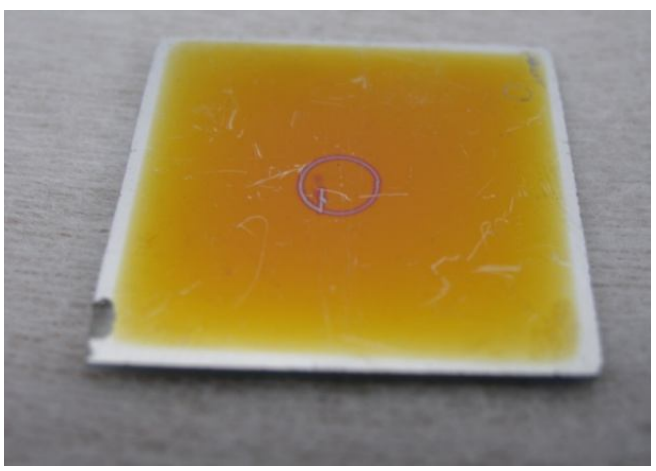

Figure 11. Photograph of etched circle on amorphous silicon deposited on glass

Amorphous silicon deposited on glass substrate is rather easy to etch: $0.5 \mathrm{~W}$ of 1064 $\mathrm{nm}$ beam can easy etch a circle on it, as seen in Figure 11.

Of course, many material properties contribute to the burning under laser beam: specific heat capacity, reflectance and absorbance at $1064 \mathrm{~nm}$, thermal conductivity, combustion with oxygen [7]. A decent modeling is necessary to optimize micromachining. In our study, we mainly base on experiment to determine the threshold power.

\section{CONCLUSION}

We have successfully developed high power $1064 \mathrm{~nm}$ operating in CW mode with $\mathrm{Nd}: \mathrm{YVO}_{4}$ as active medium. The laser performance is stable within pumping range from 0 to $11 \mathrm{~W}$. The maximum output power is 4.3 W. The Nd: $\mathrm{YVO}_{4}$ laser with concave-plane cavity is more cumbersome than $\mathrm{Nd}: \mathrm{YVO}_{4} 1 \%$ laser with plane-plane cavity, but the former showed superiority in terms of threshold pump power and slope efficiency. The laser beam can etch many kind of materials, but is most applicable to wood, plastic sheet, steel plate and silicon wafer.

\title{
LAZE DPSS PHÁT LIÊN TỤC CÔNG SUÂT CAO BƯớC SÓNG 1064 NM ÚNG DỤNG CHO GIA CÔNG BÁN DÃ̃N VÀ KIM LOẠI
}

\author{
Phan Thanh Nhật Khoa, Đặng Mậu Chiến \\ Phòng Thí nghiệm Công nghệ Nano, ĐHQG-HCM
}

TÓM TÄT: Một laze rắn bơm bằng laze bán dẫn (DPSSL) sủ dụng laze bán dân buớc sóng 808 nm làm nguồn bơm đã được xây dựng thành công. Chúng tôi sủ dụng tinh thể bất đắng hướng quang học Nd:YVO làm môi truòng hoạt tính. Ngương phát và độ dốc hiệu suất đã được đo đạc và thảo luận. Với tinh thể có nồng độ pha tạp thấp này (0,27\%) và cấu hình hệ cộng hưởng lõm-phẳng, hệ laze tỏ ra hoạt động tốt khi được bơm đến $11 \mathrm{~W}$. Chùm laze $1064 \mathrm{~nm}$ đã được đem thử nghiệm vi gia công thành công trên một số vật liệu thông thuờng nhu nhự, gỗ; bán dân nhu silicon; kim loại nhu nhôm, đồng và thép.

Tù khóa: Nd:YAG, $\mathrm{Nd}_{\mathrm{YVO}}{ }_{4}$, DPSSL, ngữ̃ng phát, độ dốc hiệu suất 


\section{REFERENCES}

[1]. Zhengping Wang, Investigation of LD end-pumped $\mathrm{Nd}: \mathrm{YVO}_{4}$ crystals with various doping levels and lengths, Optics \& Laser Technology, 33, 47-51 (2001).

[2]. W. Koechner, Solid State Laser Engineering,Springer Science \& Business Media Inc, New York, 437-440 (2006).

[3]. Richards J., Birefringence compensation in polarization coupled lasers, Appl. Opt., 26, 2514 (1987).

[4]. Y.F. Chen, Y.P. Lan and S.C.Wang, Highpower diode-end-pumped $\mathrm{Nd}: \mathrm{YVO}_{4}$ laser: thermally induced fracture versus wavelength sensitivity, Appl. Physics B, 71, 827-830 (2000).

[5]. Kogelnik H. and Li T., Laser Beams and Resonators, Applied Optics, 5, 1550-1567 (1966).

[6]. Hall D. G., Pump size effects in Nd:YAG lasers, Applied Optics, 19, 3041 (1980).

[7]. John F. Ready, Dave F. Farson, LIA Handbook Of Laser Materials Processing, Orlando: Magnolia Publishing Inc, 167170 (2001). 